\title{
Reply to letter to editor: Association between pulmonary arterial obstruction index and right lateral ventricular wall thickness with in-hospital mortality in patients with acute pulmonary embolism
}

\author{
Shahrzad Hekmati ${ }^{1}$ \\ Received: 1 February 2021 / Accepted: 8 February 2021 / Published online: 13 February 2021 \\ (C) American Society of Emergency Radiology 2021
}

Thank you for your comment about our study [1]. We completely agree with the opinion. Although we had excluded cases with motion artifacts and blurring of right ventricular borders, we believe that absence of EKG gating could have played a role in the exaggeration of right ventricular wall thickness measurements. Nonetheless, performing EKG gating had not been feasible in our everyday practice in the setting of acute pulmonary embolism. However, as you correctly mentioned, with the advent of faster CT scanners with an improved temporal resolution, this problem may be resolved in the future.

Shahrzad Hekmati

shahrzad.hek@gmail.com

1 Department of Radiology, Modarres Hospital, Shahid Beheshti University of Medical Sciences, Tehran 1989934148, Iran

\section{Declarations}

Conflict of interest The author declares no conflict of interest.

\section{Reference}

1. Faghihi Langroudi T, Shabestari AA, Hekmati S, Pourghorban R (2020) Association between pulmonary arterial obstruction index and right lateral ventricular wall thickness with in-hospital mortality in patients with acute pulmonary embolism. Emerg Radiol: 10.1007/ s10140-020-01871-5.

Publisher's note Springer Nature remains neutral with regard to jurisdictional claims in published maps and institutional affiliations. 